\title{
Unilateral lower motor neuron-type of facial palsy following snake bite presumably due to Krait (Bungarus Caeruleus)
}

\author{
Verma S', Kumar K², Arvind S3, Khadwal A4 \\ ${ }^{1}$ Dr. Sanjay Verma, ${ }^{2}$ Dr. Kunal Kumar, ${ }^{3}$ Aravind S, ${ }^{4}$ Dr. Alka Khadwal, Department of Paediatrics, Advanced Paediatric \\ Centre, Post Graduate Institute of Medical Education and Research, Chandigarh.
}

Address for correspondence: Dr. Sanjay Verma, E-mail: sanjay06verma@yahoo.com

\begin{abstract}
We describe an unusual case of snake bite presumably due to Krait (Bungarus Caeruleus) in a 12-year-old child from Mohali, Punjab. He presented with a history of bite behind his left ear, while he was sleeping at night on floor. He had bilateral ptosis, dysphonia initially, which progressed gradually to cause respiratory paralysis. Child was managed with antisnake venom, ventilation and other supportive measures. He recovered gradually, but persisted to have lower motor neuron paralysis of left facial nerve, which was noted post extubation. This uncommon presentation could be because of exposure of the facial muscles to the venom, spreading directly from the injection site and destroying the nerve terminals of facial nerve in the muscle tissue. At three months follow-up, child showed complete recovery. Facial nerve involvement following snake bite, which usually has a good prognosis, remain an uncommon presentation in paediatric age group.
\end{abstract}

Key words: Snake bite; Facial palsy, Krait

\section{Introduction}

$S^{n}$ nakebites remain a public health problem in many countries even though it is difficult to be able to be precise about the actual number of cases. According to toxicity, they are categorized as hematotoxic, neurotoxic and myotoxic. Among the neurotoxic group, the majority of bites are due to Naja Naja (Common Cobra), Ophiphagus Hannah (King Cobra) and Bungarus Caeruleus (Krait) in India'. The snake venom consists of different enzymatic and nonenzymatic components loosely categorized as neurotoxins and hemorrhagens. Neurotoxic envenomations have the potency to cause a broad spectrum of presentations starting from ptosis to respiratory arrest. We report this case of snake bite, presumably by a Krait (Bungarus Caeruleus), showing unilateral facial nerve palsy, which has been rarely reported in literature.

\section{The Case}

The patient was a 12-year-old boy from Mohali, who said he had been bitten behind his left ear by a snake at night while he was sleeping on the floor. He had pain and some oozing of blood from the bite site. One hour later he felt tingling sensation and numbness over bite site, vomited 4-5 times and experienced drowsiness. Gradually he developed dysphonia, ptosis of eyelids and weakness in all four limbs with inability to stand.

The patient presented to our emergency 4 hours after the bite. At presentation, he had altered sensorium (GCS: $E_{1} M_{5} V_{2}$ ). His heart rate was 90 beats per minute, respiratory rate 24 breaths per minute and blood pressure were $110 / 70 \mathrm{~mm}$ of $\mathrm{Hg}$. He had two fang marks behind his left ear and there was minimal swelling around this. His pupils were normally reacting to light and were normal in size. He was having bilateral ptosis and dysphonia. There was no pallor, cyanosis or any bleeding from other sites. Illness gradually progressed and within an hour, child developed respiratory difficulty and decreased power in all four limbs, for which child was intubated and put on manual ventilation.

His initial laboratory parameters revealed a hemoglobin level of $11.3 \mathrm{~g} / \mathrm{dL}$, leukocyte count 11,000 / $\mathrm{mm}^{3}$, platelet count $2,44,000 / \mathrm{mm}^{3}$, blood urea $46 \mathrm{mg} /$ $\mathrm{dL}$, serum creatinine $0.4 \mathrm{mg} / \mathrm{dL}$. Liver function test and coagulation profile was normal. In view of systemic envenomation, polyvalent antiserum venom (antivenin against cobra, common krait, Russell's viper and sawscaled viper) was administered. A total of 40 vials 
were given during the management. Tetanus toxoid immunization and intravenous antibiotics along with supportive management was also given. Child needed ventilatory support for a total of 7 days and after that his general condition improved gradually.

Neurological examination after extubation revealed facial asymmetry i.e. deviation in angle of mouth towards right side. There was drooling of saliva from left angle of mouth, collection of food in gingivobuccal sulcus on left side warranting manual removal and inability to elevate left eyebrow. Child also had complaints of numbness in the left ear lobule with hypoesthesia in surrounding skin upto the mastoid process. On this basis, he was diagnosed to have lower motor neuron type of left facial nerve palsy (Fig-1). Rest of the neurological examination was unremarkable. He also had features of autonomic instability in form of abnormal blood pressure records, for which he needed antihypertensive, which were gradually tapered and stopped. The patient was discharged from the hospital 17 days after admission. At three months follow-up, child showed complete recovery.

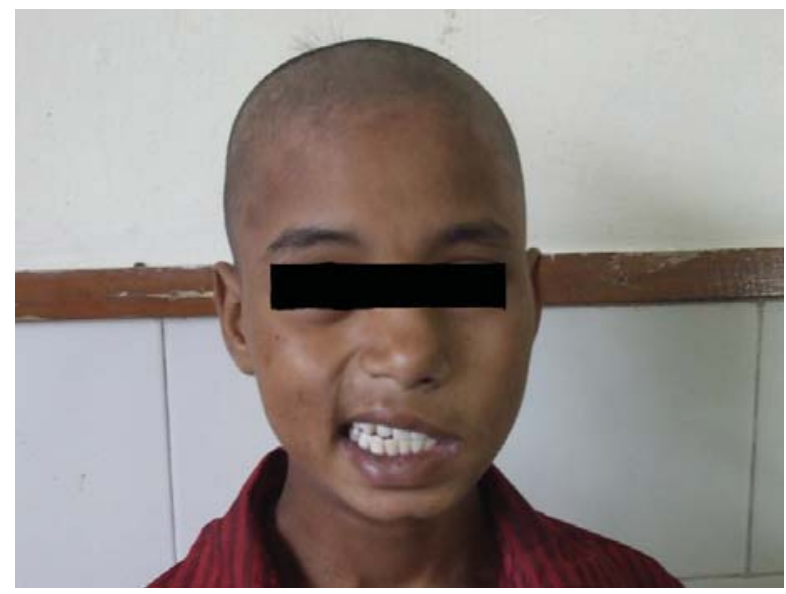

Fig 1: Facial nerve palsy following snake bite (Parental consent obtained for publication)

\section{Discussion}

The snake's venom is stored in glands which it injects to kill its natural prey. Snake venom is not a single toxin but a complex mixture of several components, including enzymes, polypeptide toxins, non-toxic proteins, carbohydrates, metals, lipids, free amino acids, nucleotides and bionic amines. Injection of these components with their various actions leads to the immediate death of small animals. However, when a snake bites a human, the dose of venom in relation to body size is too small to produce this dramatic effect. Snake envenoming of humans gives rise to an assortment of clinical manifestations which occur insidiously ${ }^{2}$.
Neurotoxins from Cobra and Kraits have two principal modes of action: (a) postsynaptic toxins produce a non-depolarizing postsynaptic neuromuscular block similar to d-tubocurarine; (b) presynaptic toxins act on the motor nerve endings, interfering specifically with the membrane process responsible for the storage and release of neurotransmitter from the motor nerve terminals ${ }^{3}$. They abolish neurotransmitter release, thus blocking neuromuscular transmission. The strength and duration of binding and decay times of the neurotoxin in the human being are not known, as far as we are aware.

Neurological complications following snake bite have been very well described in literature ${ }^{4}$. Frequently reported neurological deficits include cranial nerve palsy manifesting as ptosis, ophthalmoplegia, dysphonia, dysphagia, drooling and diplopia, with more severe presentations leading to respiratory failure and death. Cobra and Kraits usually produce selective flaccid type of neuromuscular paralysis and muscles innervated by cranial nerves often get involved. Ptosis and ophthalmoplegia are among the first symptoms found almost in all cases. Pre-synaptic as well as postsynaptic neurotoxins of cobra and krait affect mainly muscles of eye, tongue, throat and chest causing respiratory failure ${ }^{5}$. Unilateral facial palsy following snake bite is a rare but recognized complication. Only two cases of isolated facial palsy following snake bite have been reported in literature ${ }^{6,7}$. The possible explanation for such unilateral involvement could be because of exposure of the muscles to the venom, spreading directly from the injection site and destroying the nerve terminals in the muscle tissue. These enzymes/toxins act at the presynaptic site of motor end plates, first by interfering with transmitter release and finally causing destruction of the entire synaptic structure ${ }^{8}$. Due to particular innervations of facial and oculomotor muscles, they are highly susceptible to the actions of neurotoxins acting either post or presynaptically. In our case, it appears that the damage affected the motor endplates of the seventh cranial nerve in the facial muscles. It appears unlikely that damage to nerve structures was caused by an oedema of the nerve sheath in the facial nerve foramen (as in the case of Bell's palsy). Severity of envenomations and respiratory paralysis is related to dose of venom injected, potency of venom, anatomic location of bite, age, health and immune status of the victim and timely medical intervention ${ }^{9}$. The paralytic effects of snake neurotoxins, both presynaptic and post-synaptic, are temporary, generally showing resolution in hours to days (postsynaptic toxins) or days to weeks (presynaptic toxins). However, longer term or even permanent nerve damage has been recorded, but it is not a result of direct local injury from a bite near the seventh cranial nerve ${ }^{10}$. 
Facial nerve involvement following snake bite, which usually has a good prognosis; remain an uncommon presentation in pediatric age group.

\section{References}

1. Bhattacharya $P$, Chakraborty A. Neurotoxic snake bite with respiratory failure. Indian J Crit Care Med 2007;11:161-64.

2. Sanmuganathan PS. Myasthenic syndrome of snake envenomation: a clinical and neurophysiological study. Postgrad Med J 1998;74:596-99.

3. Schwersenski J, Beatty DW. Unusual features in a case of snakebite, presumably due to a Cape cobra (Naja nigricollis). S Afr Med J 1982;61:597-98.

4. Simpson ID, Norris RL. Snakes of medical importance in India: is the concept of the "Big 4" still relevant and useful? Wilderness Environ Med 2007;18:2-9.

5. Mitra S. Snake bites in India and its management. J Indian Med Assoc 1987;85:129-31.
6. Weinelt W, Sattler RW, Mebs D. Persistent paresis of the facialis muscle after European adder (Vipera berus) bite on the forehead. Toxicon 2002;40:162729.

7. Baig WW, Prabhu AR, Kumar C. Viper bite causing an isolated lower motor neuron-type of facial palsy. Singapore Med J 2009;50:368-70.

8. Lee CY, Tsai MC, Chen YM, Ritonja A, Gubensek F. Mode of neuromuscular blocking action of phospholipases $\mathrm{A}_{2}$ from Vipera ammodytes venom. Arch Int Pharmacodyn 1984;268:313-24.

9. Agarwal R, Aggarwal AN, Gupta D, Behera D, Prabhakar S, Jindal SK. Management of respiratory failure in severe neuroparalytic snake envenomation. Neurol India 2001;49;25-8.

10. Malina T, Krecsak L, Warrell DA. Neurotoxicity and hypertension following European adder (Vipera berus berus) bite in Hungary: case report and review. Q J Med 2008;101:801-6.

\section{How to cite this article?}

Verma S, Kumar K, Arvind S, Khadwal A. Unilateral lower motor neuron-type of facial palsy following snake bite presumably due to Krait (Bungarus Caeruleus). J Nepal Paediatr Soc 2012;32(2):184-186. 